\title{
Limitação do Requerimento Microbiano em Energia Metabolizável Fermentável ou Proteína Degradável na Suplementação do Pasto de Inverno de Vacas da Raça Canchim ${ }^{1}$
}

\author{
Rodolfo Marques de Brito ${ }^{2}$, Alexandre Amstalden Moraes Sampaio ${ }^{3}$, Geraldo Maria da Cruz ${ }^{4}$, \\ Maurício Mello de Alencar ${ }^{4}$, Pedro Franklin Barbosa ${ }^{4}$, Rogério Taveira Barbosa ${ }^{4}$
}

\begin{abstract}
RESUMO - Foram utilizadas 30 vacas gestantes da raça Canchim, mantidas em sistema de pastejo rotativo intensivo de capimmarandu, que receberam suplemento alimentar para manutenção de peso corporal durante a estação seca. Para avaliar as recomendações do Agricultural and Food Research Council, quanto ao fornecimento de substrato dietético para o crescimento da microbiota ruminal, os animais foram distribuídos em um delineamento inteiramente ao acaso (três tratamentos x dez repetições), de acordo com os seguintes tratamentos: controle (sem restrição do requerimento microbiano de proteína degradável e energia fermentável); restrição do requerimento microbiano de proteína degradável; e restrição do requerimento microbiano de energia metabolizável fermentável. Os suplementos foram compostos com silagem de milho, milho moído e soja integral, cujas quantidades predeterminadas foram fornecidas aos animais diariamente às $10 \mathrm{~h}$. O período de avaliação teve duração de 192 dias, durante o qual foram efetuadas pesagens dos animais no início/término de cada um dos quatro subperíodos experimentais estabelecidos. A avaliação dos resultados indicou que não houve diferença no desempenho dos animais que receberam os diferentes suplementos com médias de ganho de peso corporal de 0,$18 ; 0,02 ; \mathrm{e} 0,12 \mathrm{~kg} / \mathrm{cab} / \mathrm{dia}$ para os respectivos tratamentos descritos. Concluiu-se que a limitação do crescimento da microbiota ruminal por meio da redução dos aportes de energia fermentável ou proteína degradável não interferiu no desempenho de vacas Canchim durante o período seco.
\end{abstract}

Palavras-chave: estação seca, suplementação em pastagem, vacas

\section{Limitation of Microbial Requirements of Fermentable Metabolizable Energy or Degradable Protein in Supplementation of Winter Pasture of Canchim Cows}

\begin{abstract}
Thirty pregnant Canchim cows were maintained in a rotational grazing system of Marandu grass and received supplemental feed to body weight maintenance during the dry season. With the aim to evaluate the Agricultural and Food Research Council recommendations about supplying dietary substrate to ruminal microbial growth, the animals were allotted to a completely randomized design ( 3 treatments $x 10$ replications), according to the following treatments: control (without restriction of microbial requirements of degradable protein and fermentable energy); restriction of microbial requirement of degradable protein; and restriction of microbial requirement of fermentable metabolizable energy. The supplements were composed of corn silage, corn ground and whole soybean, in which determinate amounts were fed daily to animals at $10 \mathrm{a} . \mathrm{m}$. The evaluation period lasted 192 days and the animals were weighed at beginning/end of each one of four experimental subperiods established. The evaluated results indicated that there were no differences on performance of the animals of different treatments with body weight gain of $0.18,0.02$, and $0.12 \mathrm{~kg} / \mathrm{head} / \mathrm{day}$ in respective treatments described. It was concluded that the limitation of ruminal microbial growth through reducing of fermentable energy and degradable protein supplies did not affect the performance of Canchim cows during the dry season.
\end{abstract}

Key Words: cows, dry season, pasture supplementation

\section{Introdução}

A intensificação do sistema de produção em regiões de elevado valor da terra é requisito básico para tornar a pecuária de corte mais competitiva frente a outras modalidades de exploração agropecuária. Essa exigência conjuntural quase sempre conduz à adoção de técnicas de produção que exigem investimentos elevados, mão-de-obra qualificada e rigoroso acompanhamento técnico-científico. Entre os principais exemplos que podem ser citados destacam-se a intensificação do uso de pastagens sob lotações acima de $5 \mathrm{UA} /$ ha e a produção de animais para o abate com peso mínimo de $240 \mathrm{~kg}$ de carcaça aos 12 meses de idade por meio de recria/engorda confinada. Normalmente, a intensificação da produ-

\footnotetext{
${ }_{1}$ Projeto Fapesp n 97/06792-1 (Acordo de cooperação técnico-científica Embrapa/CPPSE e Unesp/FCAV)

2 Pós-graduando em Zootecnia (Doutorado) FCAV/Unesp - Via de acesso Prof. Paulo D. Castellanne s/n - CEP: 14884-900 - Jaboticabal (SP). Bolsista Fapesp. E.mail: rmbrito@fcav.unesp.br

${ }^{3}$ Prof. Adjunto do Depto. de Zootecnia FCAV/Unesp. Bolsista CNPq. E.mail: sampaio@fcav.unesp.br

${ }^{4}$ Pesquisador Embrapa Pecuária Sudeste (CPPSE). Home-page: http://www.cppse.embrapa.br
} 
ção gera grande entropia no sistema edafobiológico, capaz de determinar o sucesso ou fracasso da atividade em razão de detalhes mínimos, que eventualmente tenham sido negligenciados ou ainda permanecem desconhecidos. Identificar, avaliar e elucidar pequenos detalhes inerentes à intensificação dos diferentes agroecossistemas é tarefa básica da pesquisa científica de vanguarda. Nos sistemas de intensificação de uso das pastagens, em especial aqueles que adotam o sistema rotativo aliado a maciças aplicações anuais de fertilizantes, a suplementação da pastagem no período seco é componente imprescindível no manejo alimentar dos animais. Por representar um importante componente do custo de produção, a suplementação deve ser rigorosamente planejada para garantir satisfatória relação benefício-custo frente à utilização onerosa de insumos e mão-deobra, principalmente quando se considera o rebanho de matrizes.

De acordo com Laurenz et al. (1991), cerca de $65 \%$ do fluxo total de energia mobilizada na produção de carne bovina é utilizada pelo rebanho de matrizes, e aproximadamente $70 \%$ dessa fração é empregada no trabalho fisiológico de manutenção corporal, observando-se variações em razão do tamanho estrutural, da raça, do ambiente, da atividade, do nível de nutrição e ainda do potencial produtivo da vaca. Sob o paradigma de que a metade do input energético na pecuária de corte é mobilizada para manutenção da fêmea em reprodução, torna-se necessário fornecer às vacas de cria um aporte alimentar capaz de aliar a satisfação dos seus requerimentos nutricionais a uma reduzida perda de nutrientes, fato que poderia representar uma atividade catabólica desnecessária e altamente prejudicial à eficiência econômica do sistema produtivo.

A grande preocupação com essa categoria animal pode ser ilustrada pelos trabalhos de DiConstanzo et al. (1991), que procuraram métodos e formas de identificar no rebanho de matrizes os indivíduos que são energeticamente eficientes. Os autores alertaram que a herdabilidade para a demanda energética é alta, e a seleção de animais eficientes poderia ser uma ferramenta útil para a melhoria dos empreendimentos em bovinocultura de corte. Diante da importância de equacionar o manejo nutricional do rebanho destinado à reprodução e da morfofisiologia digestória desses animais, é quase sempre necessário inserir os efeitos da fermentação ruminal nas abordagens técnicas a respeito deste tema. Avaliando a importância dos problemas expostos até aqui, Hollingsworth-Jenkins et al. (1996) procuraram estabelecer os requerimentos de proteína degradável de vacas gestantes em condições específicas de produção de carne nos EUA e determinaram que o ganho de peso de vacas cruzadas Angus + Hereford + Simental + Gelbvieh apresentou comportamento quadrático $(0,05 ; 0,18$; 0,$06 ;$ e $0,01 \mathrm{~kg} / \mathrm{cab} / \mathrm{dia}$ ) para $29 ; 65 ; 100$ e $139 \%$ do requerimento de proteína degradável. Deve-se citar que trabalhos com referência ao aporte de energia fermentável não foram encontrados na literatura consultada.

Uma vez atendidos os requerimentos energéticos e protéicos do animal hospedeiro, o Sistema de Proteína Metabolizável (AFRC, 1993) recomendou que a dieta ingerida pelo animal proporcionasse o maior equilíbrio possível entre os aportes de proteína efetivamente degradável no rúmen (PDR) e energia metabolizável fermentável (EMFe) exigidas para um satisfatório crescimento microbiano no meio ruminal. Para tanto, o aporte de PDR deveria se equiparar ao aporte de EMFe, observando-se as estimativas de taxa de passagem (kp) e eficiência de síntese microbiana (y) determinadas pelo nível produtivo em que o animal se encontra, de acordo com a equação: $y \times E M F e=P D R$. Caso o suprimento de PDR permaneça abaixo do requerimento microbiano, a síntese seria limitada pela quantidade de PDR presente no meio ruminal, observando-se o mesmo efeito quando a limitação da multiplicação microbiana é determinada pela eventual falta de EMFe. Neste caso, a PDR não aproveitada pode ser perdida, o que resultaria em elevados níveis de amônia sangüínea e maior excreção de uréia, traduzidos em ineficiência nutricional da dieta e provável prejuízo econômico ao sistema.

O presente estudo procurou avaliar os efeitos na manutenção do peso corporal de matrizes Canchim gestantes, em resposta à suplementação invernal da pastagem de capim-marandu, com restrição do requerimento microbiano de energia metabolizável fermentável ou proteína degradável no rúmen, conforme preconizado pelo Sistema de Proteína Metabolizável (AFRC, 1993).

\section{Material e Métodos}

O trabalho foi conduzido em área de pastejo rotativo intensivo de capim-marandu, que recebeu aplicação de $130 \mathrm{~kg} \mathrm{~N} /$ ha na estação chuvosa anterior, conforme sugerido por Ruggieri et al. (1994). A área 
foi dividida em três módulos experimentais (3 ha/ módulo) providos de cocho para suplementação $(0,80$ $\mathrm{m}$ linear/cab) instalado na área de descanso dos animais e manejados num esquema de rodízio com seis dias de ocupação e 42 dias de descanso. Foram utilizadas 30 matrizes gestantes da raça Canchim, de 62 meses de idade, alocadas nos lotes experimentais, num esquema inteiramente ao acaso, segundo a condição e o peso corporal e ainda o tempo de gestação, visando a minimizar a interferência desses fatores na experimentação. No período que antecedeu o início do ensaio, a forragem foi amostrada (método do quadrado) e analisada quanto à PB. Também foi realizado um rápido ensaio com um bovino fistulado, conforme a técnica descrita por Vazant et al. (1998), para avaliar a degradabilidade desse nutriente, a fim de possibilitar melhor ajuste na fórmula do suplemento. O capim-marandu apresentou $44 \%$ de MS e 4,9\% de PB na MS, com disponibilidade média de $1.500 \mathrm{~kg} \mathrm{MS} / \mathrm{ha}$. As constantes de degradação da PB obtidas na estimativa da degradação in situ foram: $\mathrm{a}=13,9 ; \mathrm{b}=38,0 \%$; e c=0,0356\%/h. A partir de junho, cada lote passou a receber o suplemento de acordo com as recomendações do AFRC (1993) para manutenção de peso corporal, de acordo com os seguintes tratamentos: 1) controle (aportes equilibrados de EMFe e PDR em atendimento aos requerimentos microbianos de energia e proteína degradável); 2) restrição dos requerimentos microbianos de PDR; e 3 ) restrição dos requerimentos microbianos de EMFe.

Os alimentos utilizados para composição dos suplementos foram silagem de milho, confeccionada com plantas inteiras colhidas no estado de grão farináceo e armazenadas em trincheiras, além de soja em grão e milho moídos em peneiras com crivos de $2 \mathrm{~mm}$. Os animais receberam suplemento diariamente às $10 \mathrm{~h}$, colocando-se no cocho as quantidades de alimento preestabelecidas, misturando-se vigorosa e sistematicamente o concentrado ao volumoso, a fim de evitar seleção dos alimentos. Quando os animais completaram em média 210 dias de gestação (final do $1^{\circ}$ subperíodo experimental), os suplementos foram reajustados, para atender aos requerimentos de gestação, permanecendo dessa forma até o final do ensaio. Algumas das características raciais dos animais, necessárias para o melhor ajuste das fórmulas dos suplementos, foram consideradas conforme descreveu Alencar (1997). As fórmulas dos suplementos em cada tratamento, antes e após o reajuste, estão apresentadas na Tabela 1 .
Durante todo o período experimental não houve sobras de suplemento, e, provavelmente, devido ao satisfatório espaço linear de cocho para cada animal, não foram observadas evidências de competição pelo acesso ao cocho e, portanto, ao suplemento fornecido.

$\mathrm{O}$ período experimental subdividiu-se em três períodos de 50 dias e um quarto período de 42 dias, cuja duração foi determinada pelo retorno da estação chuvosa. Os animais foram pesados no início/término de cada subperíodo experimental, comparando-se as médias de ganho de peso corporal num esquema fatorial $3 \times 4$ (tratamentos $\mathrm{x}$ períodos) pelo teste de Tukey, a 5\% de probabilidade (Banzatto \& Kronka, 1992) e corrigindo-se o peso corporal de acordo com Ferrel et al. (1976), para minimizar o efeito da gestação sobre a variável analisada.

Os resultados da análise econômica referente aos três suplementos fornecidos foram avaliados sob dois pontos de vista da exploração pecuária do gado de corte: produção de carne e produção de touros destinados à reprodução. A avaliação econômica do sistema considerou inicialmente as receitas geradas pelo mesmo, bem como os custos de implantação (fixos) e manutenção (variáveis). No caso dos custos de implantação, agruparam-se todos os gastos efetuados dentro dos itens de despesa mais abrangentes: cercas elétricas e convencionais ( $\mathrm{R} \$$ 1.549,00/ha); material hidráulico ( $\mathrm{R} \$ 323,00 / \mathrm{ha})$; e formação da forrageira (R\$328,00/ha), totalizando R\$ 6.600,00 em cada módulo experimental (3 ha). Quanto às receitas, foram considerados os proventos específicos em ambos os tipos de exploração propostos (carne ou tourinhos para reprodução). Cada módulo possuía 10 matrizes, das quais $10 \%$ foram descartadas anualmente (abate), cedendo lugar a $20 \%$ das fêmeas oriundas do criatório e normalmente destinadas à reposição, sendo os $80 \%$ restantes destas comercializadas (R\$300,00/cab). No caso da produção de touros, haveria um aproveitamento de $40 \%$ dos animais, que seriam vendidos como reprodutores ( $\mathrm{R} \$$ $1.500,00 / \mathrm{cab}$ ), e um descarte de $60 \%$, comercializados para corte (R \$ 380,00/cab). No caso de produção de carne, todos os bezerros (exceto as fêmeas de reposição) seriam comercializados para o abate $(\mathrm{R} \$ 38,00 /$ arroba). O peso de abate das vacas foi considerado como $500 \mathrm{~kg}$, com preço de $\mathrm{R} \$ 31,00 /$ arroba e rendimento de carcaça quente de $53 \%$. A receita anual calculada para cada tipo de exploração foi de $\mathrm{R} \$ 5.887,00$ e R $\$ 3.647,00$ para a produção de tourinhos e produção de carne, respectivamente. 
Tabela 1 - Composição inicial (até 7 meses de gestação) e final (após 7 meses de gestação) dos suplementos oferecidos (kg/cab/dia) para matrizes da raça Canchim, durante a estação seca

Table 1 - Initial (until 7 months since conception) and final (after 7 months since conception) formulas of supplements offered (kg/head/ day) to Canchim cows, during the dry season

\begin{tabular}{|c|c|c|c|c|c|c|}
\hline \multirow[b]{3}{*}{$\begin{array}{l}\text { Ingrediente } \\
\text { Ingredient }\end{array}$} & \multicolumn{6}{|c|}{$\begin{array}{l}\text { Tratamento }^{1} \\
\text { Treatment }\end{array}$} \\
\hline & \multicolumn{2}{|c|}{ CTRL } & \multicolumn{2}{|c|}{ PDR } & \multicolumn{2}{|c|}{$\mathrm{EMFe}$} \\
\hline & $\begin{array}{l}\text { Inicial } \\
\text { Initial }\end{array}$ & $\begin{array}{l}\text { Final } \\
\text { Final }\end{array}$ & $\begin{array}{l}\text { Inicial } \\
\text { Initial } \\
\end{array}$ & $\begin{array}{l}\text { Final } \\
\text { Final }\end{array}$ & $\begin{array}{l}\text { Inicial } \\
\text { Initial }\end{array}$ & $\begin{array}{l}\text { Final } \\
\text { Final }\end{array}$ \\
\hline $\begin{array}{l}\text { Silagem de milho } \\
\text { Corn silage }\end{array}$ & 9,03 & 15,00 & 12,90 & 15,00 & 14,52 & 17,74 \\
\hline $\begin{array}{l}\text { Milho moído } \\
\text { Corn ground }\end{array}$ & 1,59 & 1,09 & 1,67 & 1,73 & - & - \\
\hline $\begin{array}{l}\text { Soja integral } \\
\text { Whole soybean seed }\end{array}$ & 0,99 & 0,94 & - & - & 1,06 & 1,10 \\
\hline $\begin{array}{l}\mathrm{EM}(\mathrm{MJ} / \mathrm{kg} \mathrm{MS})^{2,3} \\
M E(M J / \mathrm{kg} D M)\end{array}$ & 11,6 & 10,8 & 10,6 & 10,6 & 10,4 & 10,3 \\
\hline $\begin{array}{l}\mathrm{PB}(\% \mathrm{MS})^{3} \\
C P(\% D M)\end{array}$ & 13,6 & 12,2 & 8,9 & 8,8 & 13,1 & 12,5 \\
\hline $\begin{array}{l}\mathrm{EMFe}(\mathrm{MJ} / \mathrm{kg} \mathrm{MS}) \\
F M E(M J / \mathrm{kg} D M)\end{array}$ & 8,9 & 8,4 & 9,0 & 8,9 & 7,8 & 7,8 \\
\hline $\begin{array}{l}\text { PDR (\% MS }) \\
R D P(\% D M)\end{array}$ & 8,0 & 7,2 & 4,6 & 4,6 & 8,2 & 7,7 \\
\hline
\end{tabular}

${ }^{1}$ CTRL - controle; PDR - síntese microbiana limitada pela proteína degradável no rúmen; EMFe - síntese microbiana limitada pela energia metabolizável fermentável.

2 Energia metabolizável (EM) estimada de acordo com o AFRC (1993).

${ }^{3}$ Requerimento animal: inicial (57 MJ/dia; $415 \mathrm{~g}$ PDR/dia); final (68 MJ/dia; $473 \mathrm{~g} \mathrm{PDR/dia).}$

${ }_{1}^{1}$ CTRL - control; PDR - microbial synthesis limited by ruminal degradable protein; EMFe - microbial synthesis limited by fermentable metabolizable energy.

2 Metabolizable energy (ME) estimated in accordance with AFRC (1993).

${ }^{3}$ Animal requirement: initial ( $\left.57 \mathrm{MJ} / \mathrm{d} ; 415 \mathrm{~g} R D P / d\right)$; final (68 MJ/d; $\left.473 \mathrm{~g} R D P / d\right)$.

\section{Resultados e Discussão}

Os resultados da análise estatística do ganho de peso corporal em cada subperíodo e ao longo do período experimental bem como dos pesos dos animais de cada lote no início e término do ensaio estão apresentados na Tabela 2. Não houve diferenças entre os tratamentos em nenhuma das médias avaliadas, ressaltando-se a proximidade absoluta entre o peso inicial e final do tratamento em que se procurou restringir a síntese microbiana pelo déficit de PDR. É preciso lembrar que a eventual restrição deu-se no rúmen, pois em todos os casos os requerimentos do animal hospedeiro (energia e proteína) foram integralmente atendidos, o que também poderia explicar a ausência de diferenças.

O trabalho desenvolvido por Ortigues et al. (1993) pode corroborar os resultados aqui obtidos, uma vez que aqueles autores forneceram suplementação de inverno de $113 \mathrm{kcal} / \mathrm{kg} \mathrm{PC} \mathrm{PC}^{0,75}$ para matrizes charolesas, próximo do nível utilizado no presente trabalho, obtendo ganho de peso corporal de $46 \mathrm{~g} / \mathrm{cab} / \mathrm{dia}$.
Como os autores não obtiveram diferenças no coeficiente de digestibilidade aparente de matéria orgânica, energia bruta e nitrogênio, em relação ao grupo controle (74 kcal/kg PV ${ }^{0.75}$ ) em 116 dias de suplementação, pode-se supor que, no nível de manutenção $(\mathrm{L}=1)$, eventuais diferenças na produção de massa microbiana causadas por alterações nos padrões de fermentação ruminal podem não ser substancialmente significativas, uma vez que os requerimentos mínimos do animal nesse nível produtivo sejam atendidos.

A média geral dos tratamentos avaliados $(0,1 \mathrm{~kg} /$ cab/dia) esteve próxima do valor preconizado pelo AFRC (1993) quando do ajuste do suplemento para manutenção de peso corporal, o que garantiu pequena margem de segurança para dietas destinadas a esse manejo nutricional, considerando-se a possibilidade de uma pequena contribuição da pastagem, apesar da baixa qualidade do capim durante a estação seca. As diferenças obtidas entre períodos denotam a clara necessidade de suplementar a pastagem no período de entressafra, pois mesmo com o reajuste dos suple- 
Tabela 2 - Peso corporal ao inicio e término do período experimental e ganho de peso corporal - GPC (kg/animal/dia) proporcionado pelos diferentes tratamentos em cada período de avaliação

Table 2 - Initial and final body weight and body weight gain - BWG ( $\mathrm{kg} / \mathrm{head} / \mathrm{day})$ provided by the different treatments in each evaluation period

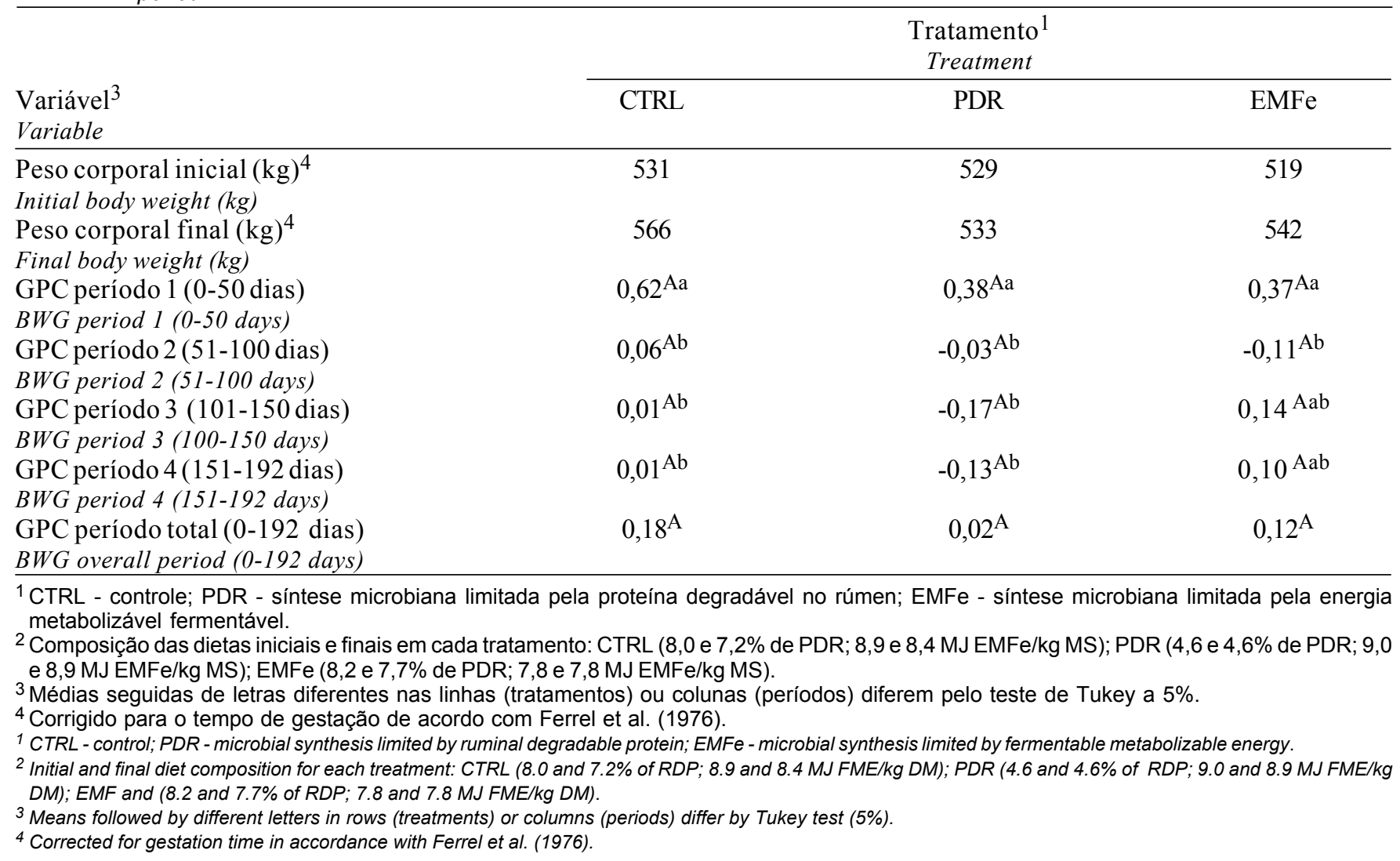

mentos, aumentando-se o aporte nutricional, os animais apresentaram, nos períodos finais, desempenho inferior ao apresentado no período inicial, o que indica a acentuada queda da qualidade da forragem. Cite-se ainda que os animais apresentaram durante todo o período experimental uma condição corporal em torno de 7, fator que dificultou a tarefa de suplementação, mas permitiu índices de concepção de $90 \%$ (dados não publicados) na estação de monta imediatamente posterior a este trabalho.

Os resultados indicaram que, uma vez satisfeitas as exigências do hospedeiro, permitir a síntese microbiana de forma irrestrita (caso do suplemento controle) pode não ser interessante do ponto de vista econômico, já que ao final do período, seria registrado um sensível diferencial médio de cerca de $\mathrm{R} \$ 28,72$, do tratamento controle em relação aos demais, se considerados apenas os custos do alimento. A opção de arraçoamento deve ater-se, portanto, às condições de disponibilidade e preço dos ingredientes que deverão ser utilizados. No atual contexto da pecuária de corte, os resultados devem ser analisados em conjunto com as avaliações econômicas referentes aos tratamentos testados. Essa integração de informações possibilitaria a avaliação de alternativas de emprego das técnicas estudadas e ainda propiciaria maiores chances de sucesso quando da adoção das mesmas. Constam na Tabela 3 os balanços econômicos gerais de cada um dos módulos de pesquisa, agregando o efeito do custo da suplementação dos diferentes tratamentos, o que forneceu bom indicativo da importância desse fator e ainda esclareceu o diferencial obtido em cada lote, de acordo com a abordagem produtiva (carne $\mathrm{x}$ touros) escolhida.

Observou-se que nenhum dos módulos experimentais de produção apresentou rentabilidade positiva quando a intensificação do modelo de produção visou à produção de bezerros para corte, com prejuízos de $\mathrm{R} \$ 308,97$; $\mathrm{R} \$ 212,80$; e $\mathrm{R} \$ 202,14 / \mathrm{ha} /$ ano, para os sistemas que empregaram os suplementos de controle, com limitação de PDR e com limitação de EMFe, respectivamente. No caso de produção de animais 
para a reprodução, os lucros líquidos foram de $\mathrm{R} \$ 437,69$; $\mathrm{R} \$ 533,86$; e $\mathrm{R} \$ 544,52 / \mathrm{ha} /$ ano para os sistemas de produção com suplementos de controle, limitante em PDR e limitante em EMFe, respectivamente, indicando um grande potencial de remuneração econômica nessa modalidade de exploração de bovinos de corte.

Neste caso, a taxa de remuneração mensal sobre o capital investido esteve ao redor de $2,5 \%$ ao mês, o que pode representar significativa diferença em relação a outras aplicações financeiras, considerando que à ocasião da realização deste trabalho a mais popular aplicação - caderneta de poupança - proporcionou aos investidores taxas mensais ao redor de $0,60 \%$.

É preciso ressaltar o sensível diferencial em relação a esse valor de mercado quando se consideram as taxas de remuneração mensal obtidas no sistema destinado à produção de tourinhos, constituindo tal atividade em atraente opção para investimen- tos que visam à multiplicação substancial do capital empregado, já que a rentabilidade gerada aproximouse de R \$500,00/ha/ano. Em ambos os modelos produtivos, carne e touros, notou-se o diferencial produzido entre os tratamentos pela variação no custo do suplemento utilizado: o sistema em que foi adotado o suplemento limitante em EMFe proporcionou rentabilidades superiores de $29,10 \%$ em relação ao sistema com suplemento controle, no caso da produção de touros para reprodução, sem reflexos nos resultados de desempenho. Sob o ponto de vista inverso, no caso da exploração para carne o mesmo tratamento controle foi $47,24 \%$ mais antieconômico que o sistema que empregou o suplemento limitante em EMFe, embora este também tenha apresentado resultado insatisfatório. É necessário considerar que a adoção de suplementos com restrição de EMFe (que apresentou menor prejuízo) não deve implicar em elevadas ingestões de PDR, sob pena de modificações no

Tabela 3 - Análise econômica da restrição de proteína degradável ou energia fermentável no ajuste de dieta suplementar para vacas da raça Canchim durante o período seco em modelos físico-estruturais de produção de carne ou produção de tourinhos 1

Table 3 - Economic analysis of restriction of degradable protein or fermentable energy in adjustment of supplemental diet to Canchim cows during the dry season in physic-structural models of meat production or sire production ${ }^{1}$

\begin{tabular}{|c|c|c|c|c|c|c|}
\hline \multirow[b]{2}{*}{ Item } & \multicolumn{2}{|c|}{ CTRL } & \multicolumn{2}{|c|}{ PDR } & \multicolumn{2}{|c|}{$\mathrm{EMFe}$} \\
\hline & $\begin{array}{l}\text { Carne } \\
\text { Meat }\end{array}$ & $\begin{array}{l}\text { Touro } \\
\text { Sire }\end{array}$ & $\begin{array}{l}\text { Carne } \\
\text { Meat }\end{array}$ & $\begin{array}{l}\text { Touro } \\
\text { Sire }\end{array}$ & $\begin{array}{l}\text { Carne } \\
\text { Meat }\end{array}$ & $\begin{array}{c}\text { Touro } \\
\text { Sire } \\
\end{array}$ \\
\hline Custo fixo comum ${ }^{3}$ & 660,00 & 660,00 & 660,00 & 660,00 & 660,00 & 660,00 \\
\hline $\begin{array}{l}\text { Common fix cost } \\
\text { Custos variáveis comuns } 4 \\
\text { Common variable costs }\end{array}$ & $1.922,16$ & $1.922,16$ & $1.922,16$ & $1.922,16$ & $1.922,16$ & $1.922,16$ \\
\hline $\begin{array}{l}\text { Custo de suplementação } \\
\text { Supply cost }\end{array}$ & $1.732,87$ & $1.732,87$ & $1.460,69$ & $1.460,69$ & $1.430,50$ & $1.430,50$ \\
\hline $\begin{array}{l}\text { Subtotal } \\
\text { Subtotal }\end{array}$ & $4.315,03$ & $4.315,03$ & $4.042,85$ & $4.042,85$ & $4.012,66$ & $4.012,66$ \\
\hline $\begin{array}{l}\text { Juros } \mathrm{s} \text { / capital investido } \\
\text { Interest on invested capital }\end{array}$ & 258,90 & 258,90 & 242,57 & 242,57 & 240,76 & 240,76 \\
\hline $\begin{array}{l}\text { Total custos } \\
\text { Total cost }\end{array}$ & $4.573,93$ & $4.573,93$ & $4.285,42$ & $4.285,42$ & $4.253,42$ & $4.253,42$ \\
\hline $\begin{array}{l}\text { Receita } \\
\text { Income }\end{array}$ & $3.647,00$ & $5.887,00$ & $3.647,00$ & $5.887,00$ & $3.647,00$ & $5.887,00$ \\
\hline $\begin{array}{l}\text { Líquido } \\
\text { Net profit }\end{array}$ & $-926,93$ & $1.313,07$ & $-638,42$ & $1.601,58$ & $-606,42$ & $1.633,58$ \\
\hline $\begin{array}{l}\text { Remuneração mensal (\%) } \\
\text { Monthly remuneration }\end{array}$ & $-1,87$ & 2,13 & $-1,34$ & 2,68 & $-1,27$ & 2,75 \\
\hline
\end{tabular}

1 Valores expressos em R\$ (reais), exceto Remuneração mensal. (R\$2,00 = US $\$ 1,00)$.

2 CTRL - controle; PDR - síntese microbiana limitada pela proteína degradável no rúmen; EMFe - síntese microbiana limitada pela energia metabolizável fermentável.

3 Depreciação da infra-estrutura - R $\$ 660,00$.

4 Adubo (130 kg N/ha/ano) - R\$ 877,50; Peão (0,33 homens/ano) - R\$866,66; Medicamentos (ano) - R\$ 100,00; Sal mineral (260 kg/ano) - R\$ 78,00 .

1 Values are expressed in $R \$$ (reais), except for monthly remuneratin ( $R \$ 2.00=U S \$ 1.00)$.

2 CTRL - control; PDR - microbial synthesis limited by rumen degradable protein; EMFe - microbial synthesis limited by fermentable metabolizable energy.

3 Facilities maintenance - $R \$ 660,00$.

4 Fertilizer (130 kg/ha/year) - $R \$ 877.50$; Employee (0.33 man/year) - $R \$ 866.66$; Veterinary drugs (year) - $R \$ 100.00$; Mineral premix (260 kg/year). 
ambiente uterino e conseqüente redução na viabilidade embrionária, fruto de alterações no transporte iônico endometrial, em razão do excesso de amônia e uréia circulantes (Robinson, 1996). Estes resultados atestaram a vital importância que deve ser despendida em relação ao manejo nutricional dos animais para que se obtenha sucesso na atual pecuária de corte, que deve agregar baixo custo produtivo a desempenhos biológicos adequados.

\section{Conclusões}

A suplementação para vacas da raça Canchim durante a estação seca, limitando-se o requerimento microbiano de proteína degradável ou energia fermentável, não diferiu do tratamento controle (sem limitação), devendo optar-se por suplementos cuja disponibilidade e/ou custo dos ingredientes seja mais acessível.

\section{Literatura Citada}

AGRICULTURAL AND FOOD RESEARCH COUNCIL AFRC. Energy and protein requirements of ruminants, Wallingford: CAB International, 1993. 59p.

ALENCAR, M.M. Pesquisa na raça Canchim. In: CONVENÇÃO NACIONAL DA RAÇA CANCHIM, 3., 1997, São Carlos. Anais... São Carlos: Embrapa-CPPSE/São Paulo: ABCCAN, 1997. p.77-93.

BANZATTO, D.A.; KRONKA, S.N. Experimentação agrícola. 2.ed. Jaboticabal: Funep, 1992. 247p.

DiCONSTANZO, A.; MEISKE, J.C.; PLEGGE, S.D. Characterization of energetically efficient and inefficient beef cows. Journal of Animal Science, v.69, p.1337-1348, 1991.

FERREL, C.L.; GARRET, W.N., HINMAN, N. Growth, development and composition of the udder and gravid uterus of beef heifers during pregnancy. Journal of Animal Science, v.42, n.6, p.1477-1489, 1976.
HOLLINGSWORTH-JENKINS, K.J.; KLOPFENSTEIN, T.J.; ADAMS, D.C. et al. Ruminally degradable protein requirement of gestating beef cows grazing native Sandhills range. Journal of Animal Science, v.74, p.1343-1348, 1996.

LAURENZ, J.C.; BYERS, F.M.; SCHELLING, G.T. et al. Effects of season on the maintenance requirements of mature beef cows. Journal of Animal Science, v.69, p.2168-2176, 1991.

ORTIGUES, I.; PETIT, M.; AGABRIEL, J. et al. Maintenance requirements in metabolizable energy of adult, non pregnant, nonlactating Charolais cows. Journal of Animal Science, v.71, n.7, p.1947-1956, 1993.

ROBInSON, J.J. Nutrition and reproduction. Animal Reproduction Science, v.42, n.1, p.25-34, 1996.

RUGGIERI, A.C.; FAVORETTO, V.; MALHEIROS, E.B. Caraterísticas de crescimento e produção de matéria seca da Brachiaria brizantha (Hochst) Stapf. cv. Marandu em função de níveis de nitrogênio e regimes de corte. Boletim de Indústria Animal, v.51, n.2, p.149-155, 1994.

VAZANT, E.S.; COCHRAN, R.C.; TITGEMEYER, E.C. Standardization of in situ techniques for ruminant feedstuff evaluation. Journal of Animal Science, v.76, n. 10, p.27172729, 1998.
Recebido em: 25/03/01 Aceito em: 24/09/01 